\title{
Prospect of Tunneling Green Transistor for 0.1V CMOS
}

Chenming $\mathrm{Hu}^{1 *}$, Pratik Patel ${ }^{1}$, Anupama Bowonder ${ }^{1}$, Kanghoon Jeon ${ }^{1,2}$, Sung Hwan Kim ${ }^{1}$, Wei Yip Loh ${ }^{2}$, Chang Yong Kang ${ }^{2}$, Jungwoo $\mathrm{Oh}^{2}$, Prashant Majhi ${ }^{2}$, Ali Javey ${ }^{1}$, Tsu-Jae King Liu ${ }^{1}$, Raj Jammy ${ }^{2}$

${ }^{1}$ Dept. of Electrical Eng. and Computer Science, University of California, Berkeley, USA;

${ }^{2}$ International SEMATECH, Austin, TX 78741, USA.*Tel: 1-510-642-3393, Fax: 1-510-642-2739, E-mail: hu@eecs.berkeley.edu

\section{Abstract}

Well designed tunneling green transistor may enable future VLSIs operating at $0.1 \mathrm{~V}$. Sub-60mV/decade characteristics have been convincingly demonstrated on 8 " wafers. Large $\mathrm{I}_{\mathrm{ON}}$ at low $\mathrm{V}_{\mathrm{DD}}$ are possible according to TCAD simulations but awaits verification. $\mathrm{V}_{\mathrm{DD}}$ scaling will greatly benefit from low (effective) band gap energy, which may be provided by type II heterojunctions of $\mathrm{Si} / \mathrm{Ge}$ or compound semiconductors.

\section{A Looming Barrier to IC Scaling}

Reducing the voltage $\mathrm{V}_{\mathrm{DD}}$ is a powerful way to reduce IC energy consumption, which is proportional to $\mathrm{V}_{\mathrm{DD}}{ }^{2}$. Power usage was kept under control when $\mathrm{V}_{\mathrm{DD}}$ was reduced in proportion to half-pitch up to $130 \mathrm{~nm}$ as shown in Fig 1 [1]. The $14 \mathrm{~nm}$ node is projected to operate at $0.7 \mathrm{~V}$, making the power consumption $25 \mathrm{x}$ larger than it would be if operated at $0.14 \mathrm{~V}$ as the past trend suggests. While IC power consumption has been much discussed as a thermal management challenge, it is also responsible for a few percent of the electricity usage and growing fast. MOSFET current cannot rise faster than one decade for every $60 \mathrm{mV}$ increase in $\mathrm{V}_{\mathrm{g}}$ (the subthreshold swing, $\mathrm{SS}$ ). To reduce $\mathrm{V}_{\mathrm{DD}}$ to $0.14 \mathrm{~V}$ with $\mathrm{I}_{\mathrm{ON}} / \mathrm{I}_{\mathrm{OFF}}$ ratio of mere 3 decades, $\mathrm{SS}$ needs to be $45 \mathrm{mV} /$ decade. A low voltage transistor (Green Transistor, $\mathrm{gFET}$ ) is needed.

\section{Green Transistor with Steep Turn On/Off}

In MOSFETs (and BJTs), a potential barrier is raised and lowered by $\mathrm{V}_{\mathrm{g}}$ to turn the current on and off (Fig. 2). Due to Boltzmann distribution, some electrons always have sufficient energy to pass over the barrier. The current can only be reduced by the rate of electron density drop with increasing energy, hence the $60 \mathrm{mV} /$ decade limit [1]. To beat this limit, the carriers must not flow over a barrier. They may tunnel through it.

Fig. 3 shows a prototype tunnel transistor [1-4]. Electrons are generated by band-to-band tunneling in the $\mathrm{P}+$ source when the gate voltage bends the energy band to satisfy two conditions - overlap of the valence and conduction bands and the a high electric field or thin tunnel barrier [5]. The generated electrons flow through the surface $\mathrm{N}$-channel to the drain. Fig. 4 shows simulated $\mathrm{I}_{\mathrm{d}}-\mathrm{V}_{\mathrm{g}}$ [6] assuming uniform source doping. In all $>3 \mathrm{E} 19 \mathrm{~cm}^{-3}$ cases, steep turn on occurs at the onset of band overlap. Unfortunately the graded source doping profile and the averaging effect of the Poisson equation provide a continuous range of (effective) doping concentration near the tip of the source. At points of lower doping (Fig. 4) the turn-on voltages and electric field (therefore $\mathrm{I}_{\mathrm{ON}}$ ) are both lower. The envelope of these curves is the IV of a prototype tunnel transistor, with a disappointing sub- $\mathrm{V}_{\mathrm{t}}$ swing.

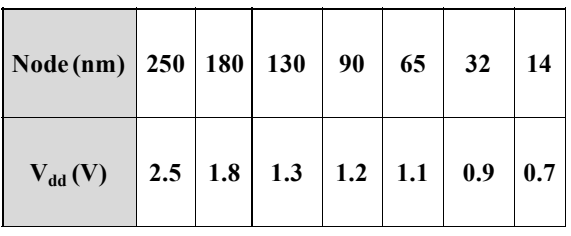

Fig. 1. IC $V_{D D}$ scaling history and ITRS projection. Slowdown since $90 \mathrm{~nm}$ leads to accelerated rise in energy consumption.



Fig. 2. Boltzmann statistics lead to the $60 \mathrm{mV} /$ decade limit because current is controlled with an energy barrier [1].

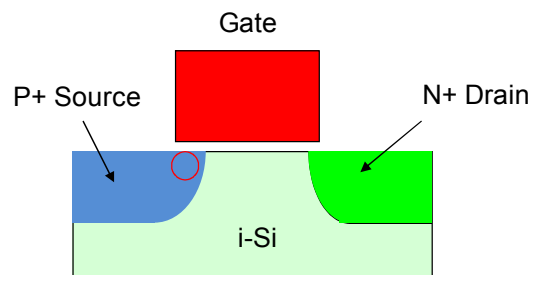

Fig. 3. In a prototype N-type tunnel transistor, electrons are generated by tunneling in the red-circle region.

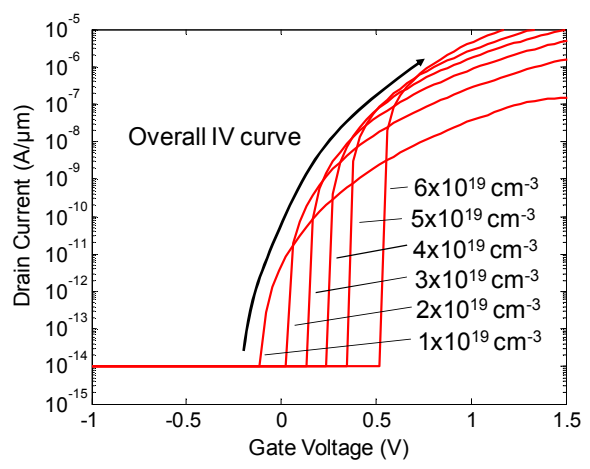

Fig. 4. Simulated $I_{D S}$ is varied with source doping. Envelope of the curves leads to a poor sub- $\mathrm{V}_{\mathrm{t}}$ swing of a tunneling transistor. 
Fig. 5 shows a design that lowers the turn-on voltage of the heavily doped part of the source [1]. Fig. 6 shows the evolution of the IV of Si gFETs of this type as the pocket doping is increased [6]. Fig. 7 illustrates the concept of steep turn on at the sudden onset of the overlap of the conduction and valence bands.

Another approach is to use a very steep source doping profile to minimize the size of the low doping part of the source (but not the Poisson averaging effect). Fig. 8 shows that sub- $60 \mathrm{mV} /$ decade average $\mathrm{SS}$ is achieved over six orders of magnitude of current with a device similar to Fig. 3 but fabricated on Si SOI substrate with a Ge source [7]. After gate and drain formation, the source region was etched and refilled with insitu doped poly-Ge at low temperature. Fig. 9 shows yet another gFET design that produces steep turn on/off. The graded source region is minimized with dopant segregation from $\mathrm{NiSi}$ and a thin semiconductor pocket is created between the gate dielectric and underlying NiSi [8]. The vertical electric field is enhanced in the thin pocket to further reduce the source edge effect. The measured 46 $\mathrm{mV} /$ decade SS could only be reproduced by simulation when a semiconductor pocket is present as shown is Fig. 9. Fig. 10 shows the X-SEM images of the device with a wedge-shaped pocket between the silicide and the gate dielectric. This geometry is produced by recessing the source before the salicide steps. A control device without the pocket was also fabricated for comparison. Fig. 11 shows the measured $\mathrm{I}_{\mathrm{D}}-\mathrm{V}_{\mathrm{G}}$ characteristics of the gFET vs. the control device. The minimum SS of the gFET is $46 \mathrm{mV} / \mathrm{dec}$. Another lot successfully reproduced the result two months later with $47 \mathrm{mV} / \mathrm{dec}$ SS. As seen in Fig. 12, the gFET shows sub- $60 \mathrm{mV} / \mathrm{dec}$ SS over 3 decades of drain current. Special care must be taken to screen out low SS data due to various causes (Fig. 14). Statistical distributions of swing show that more than $30 \%$ of the gFETs on an 8 " wafer have sub- $60 \mathrm{mV} / \mathrm{dec}$ SS (Fig. 15). The measured $\mathrm{I}_{\mathrm{D}}-\mathrm{V}_{\mathrm{D}}$ characteristics of the gFET (Fig. 16) are similar to MOSFET's.

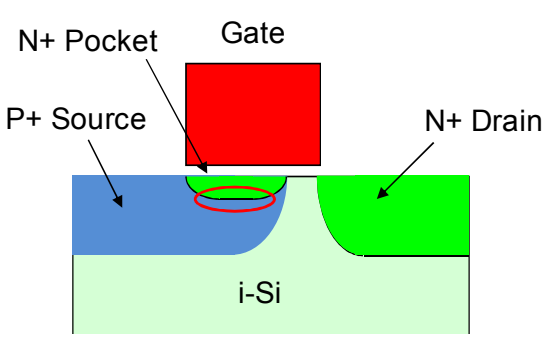

Fig. 5. One design of a low SS swing gFET. The $\mathrm{N}$ pocket lowers the turn-on voltage of the heavily doped source region.

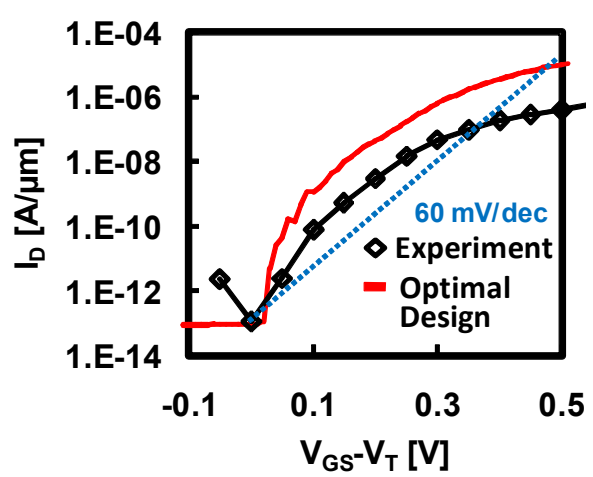

Fig. 8. Deposited insitu doped Ge source gFET produced sub- $60 \mathrm{mV} /$ dec. average SS measured over 6 orders of current [7].

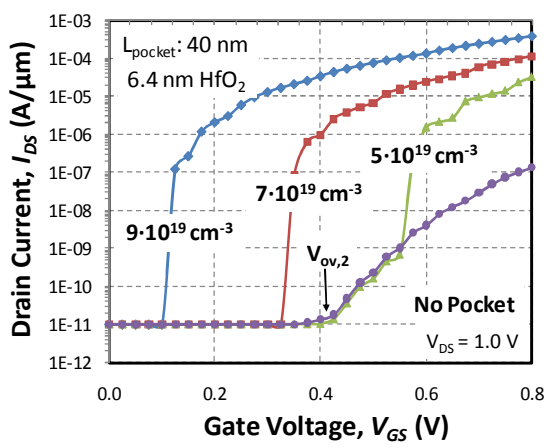

Fig. 6. $N$ pocket doping reduces the turn-on voltage. Uniform 5E19 $\mathrm{cm}^{-3}$ doped $\mathrm{P}+$ source. TCAD simulation.

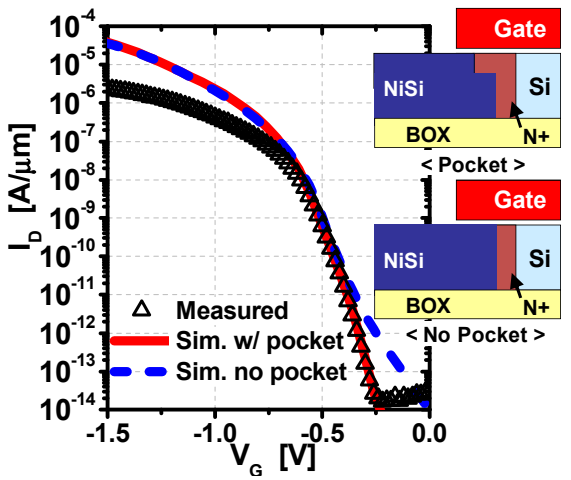

Fig. 9. Another design achieves less than $60 \mathrm{mV} / \mathrm{dec}$. swing with a semiconductor pocket between oxide and metal (NiSi) [8].

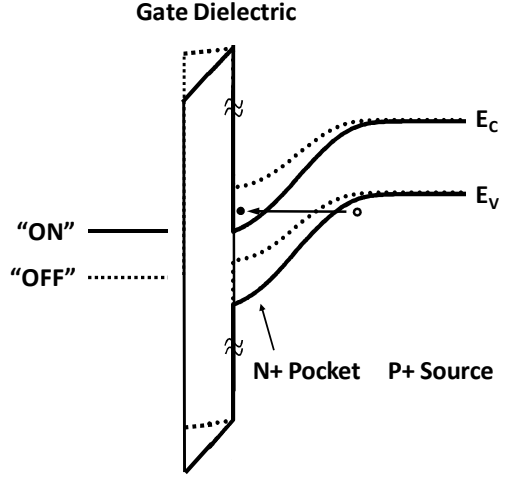

Fig. 7. Energy diagram from gate through pocket to source. Device is off when there is no overlap of valence and conduction bands.

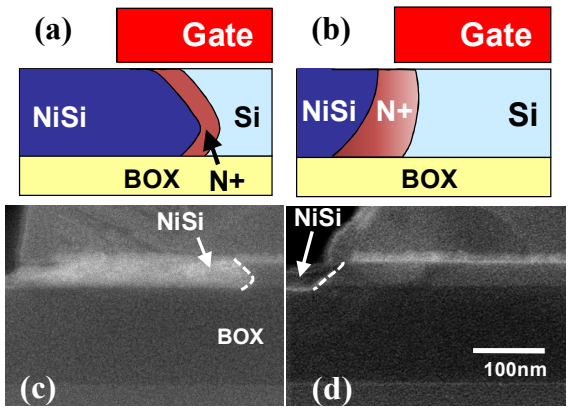

Fig. 10. Structure and cross-section SEM at source side of dopant segregated gFET (a), (c) and control device (b), (d). [8] 
Prospects of Large $I_{O N}$ at $0.1 \mathrm{~V} V_{D D}$

Simulations show that $\mathrm{V}_{\mathrm{DD}}$ can be scaled by reducing $\mathrm{E}_{\mathrm{g}}$ (Fig. 17). Only $E_{g}$ was reduced in simulation, not any other tunneling parameters [1]. At $\mathrm{E}_{\mathrm{g}}=0.36 \mathrm{eV} \quad \mathrm{I}_{\mathrm{ON}}$ exceeds $1 \mathrm{~mA} / \mu \mathrm{m}$ at $\mathrm{V}_{\mathrm{DD}}=0.2 \mathrm{~V}$ with $\mathrm{CV} / \mathrm{I}=0.4 \mathrm{pS}$ and can operate well at $0.1 \mathrm{~V}$ (Fig. 18). A type II hetero-junction gFET [9] provides an effective tunneling band gap $\left(\mathrm{E}_{\text {geff }}\right)$ lower than the $\mathrm{E}_{\mathrm{g}}$ of both materials (Fig. 19, 20). Materials A and B can be simply strained $\mathrm{Si}$ thin film on Ge for N-gFET with theoretical $\mathrm{E}_{\text {geff }}$ of around $0.18 \mathrm{eV}$ (Fig. 21), suitable for $0.1 \mathrm{~V}$ gFET. Strained Ge on $\mathrm{Si}$ is attractive for P-gFET. A and B can be compound semiconductors such as InAs on $\mathrm{AlGaSb}$ with $\mathrm{E}_{\text {geff }}$ adjustable through the $\mathrm{Ga} / \mathrm{Sb}$ ratio (Fig. 22). The low density-of-states and strong quantization of low effective-mass materials pose a serious challenge to gFET design.

\section{Conclusion}

Carefully designed tunneling green transistors can potentially enable $0.1 \mathrm{~V}$ ICs. Sub- $60 \mathrm{mV} / \mathrm{dec}$ subthreshold swing has been demonstrated on 8 "' wafers with statistical data. High current and low voltage operation needs small effective band gap energy which may be provided by type II heterojunctions of $\mathrm{Si} / \mathrm{Ge}$ or compound semiconductors. gFET in Fig. 5 is insensitive to gate length variations
(Fig. 23) because the tunnel path is enclosed in the source and shielded from the influence of the drain.

\section{Acknowledgement}

Work is partially supported by DARPA under a SPAWAR contract, \#N66001-08-C-2022, FCRP/MSD, and NSF STC/E3S.

\section{References}

[1] C. Hu, D. Chou, P. Patel and A. Bowonder, International Symposium on VLSI Technology, Systems and Applications, p. 14-15, April, 2008.

[2] W. Choi, B.G.Park, J.D. Lee and T.J.K. Liu, IEEE-EDL vol. 28, no.8, p.743, 2007.

[3] F. Mayer et al., IEDM Tech Dig., p.163, 2008.

[4] T. Krishnamohan, D. Kim, S. Raghunathan and D. Saraswat, IEDM Tech Dig., p.947, 2008.

[5] T.Y. Chan, J. Chen, P.K. Ko and C.Hu, IEDM Tech Dig., p.718, 1987. [6] P. Patel, K. Jeon, A. Bowonder and C.Hu, SISPAD 2009. pp. 1-4, Sept. 2009.

[7] S.H.Kim, H.Kam, C.Hu and T.J.K. Liu, VLSI Tech. Dig., pp.178-179, June 2009.

[8] K. Jeon et al., VLSI Tech. Dig., pp. 65-66, June 2010.

[9] A. Bowonder et al., International Workshop on Junction Tech., p. 93, 2008.

[10] C.G.Van der Walle and R.M. Martin, Phys. Rev. B, vol. 38(8), p.5621, 1986.

[11] M. M. Rieger and P. Vogl, Phys. Rev. B, vol. 48(19), p.14276, 1993.

[12] L. Yang et al., Semicon. Sci. Tech. vol. 19(10), p.1174, 20



Fig. 11. $I_{D}-V_{G}$ of measured gFET showing $S S$ of $46 \mathrm{mV} /$ dec. $\left(\mathrm{L}_{\mathrm{G}}=20 \mu \mathrm{m}, \mathrm{V}_{\mathrm{DS}}=-1.0 \mathrm{~V}\right)$

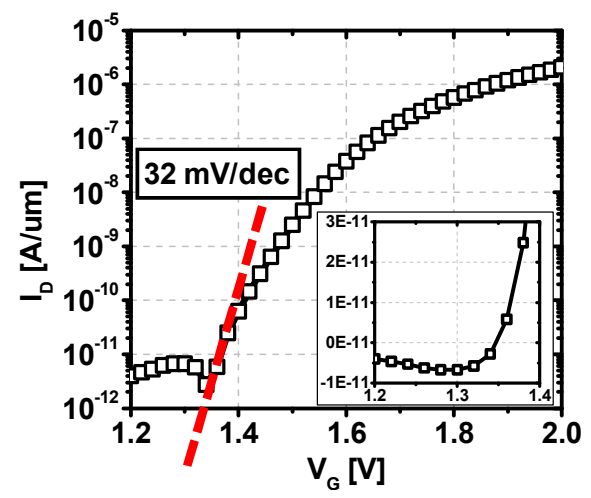

Fig. 14. Phantom low SS can show up without proper screening.

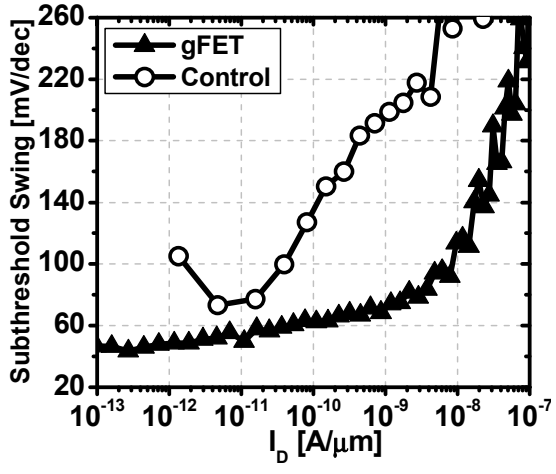

Fig. 12. SS $<60 \mathrm{mV} / \mathrm{dec}$ over almost 3 decades of $I_{D}$ for the gFET, but not seen in the control tunnel transistor.

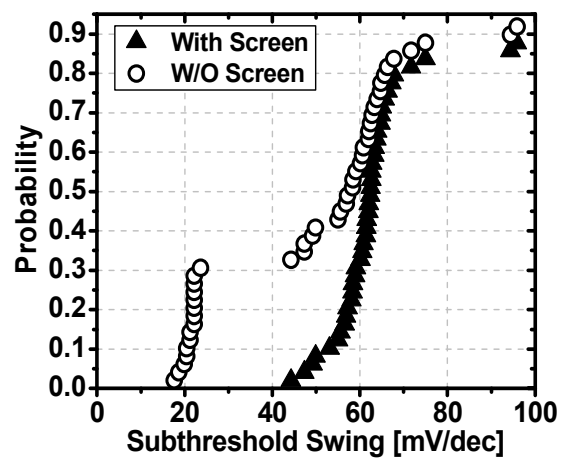

Fig. 15. SS distribution comparison of gFET swing with and without proper screen [8].

\begin{tabular}{|c|c|c|c|c|}
\hline & $\begin{array}{c}\text { Ref. } \\
{[2]}\end{array}$ & $\begin{array}{c}\text { Ref. } \\
{[3]}\end{array}$ & $\begin{array}{c}\text { Ref. } \\
{[4]}\end{array}$ & $\begin{array}{c}\text { This } \\
\text { Work }\end{array}$ \\
\hline $\begin{array}{c}\text { SS } \\
(\mathrm{mV} / \mathrm{dec})\end{array}$ & 52.8 & 42 & $\sim 300$ & 46 \\
\hline $\begin{array}{c}\mathbf{I}_{\mathrm{ON}} \\
(\mu \mathrm{A} / \mu \mathrm{m})\end{array}$ & 12.1 & 0.01 & $1 \mathrm{E}-4$ & 1.2 \\
\hline $\mathbf{I}_{\text {ON }} / \mathbf{I}_{\text {OFF }}$ & $1 \mathrm{E} 4$ & $1 \mathrm{E} 4$ & $1 \mathrm{E} 2$ & $7 \mathrm{E} 7$ \\
\hline
\end{tabular}

Fig. 13. Comparison with other reported silicon tunnel transistors [8]. $\mathrm{V}_{\mathrm{DS}}=$ $\mathrm{V}_{\mathrm{GS}}-\mathrm{V}_{\mathrm{BTBT}}=1.0 \mathrm{~V}$.



Fig. 16. Measured $I_{D}-V_{D}$ of gFET showing typical tunneling transistor behavior [8]. 


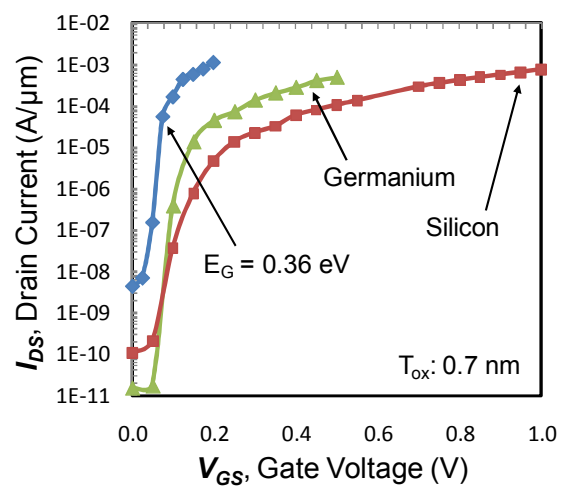

Fig. 17. Reducing the $E_{g}$ is a new path for scaling the $\mathrm{V}_{\mathrm{DD}}$ for ICs. $\mathrm{CV} / \mathrm{I}$ is $\sim<1 \mathrm{pS}$. Only $E_{g}$ is varied in simulation [1].

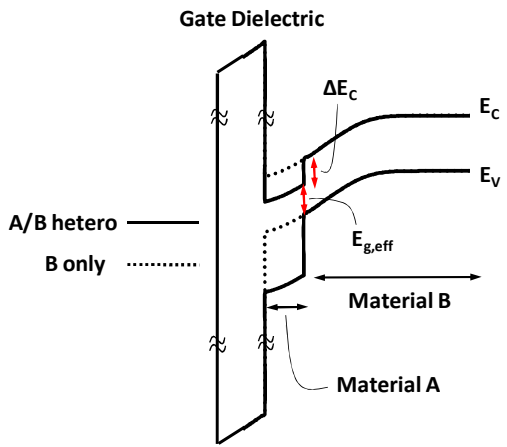

Fig. 20. The effective tunneling band gap in Type II heterojunction is smaller than those of $\mathrm{A}$ and $\mathrm{B}$ alone [9].

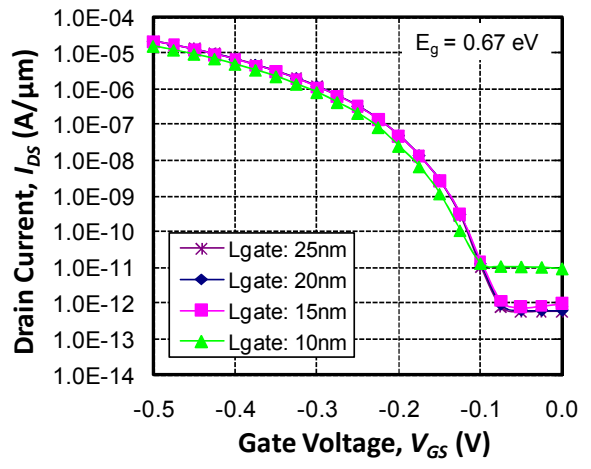

Fig. 23. Simulated gFET IV is insensitive to $\mathrm{L}_{\mathrm{G}}$ variation because the tunneling region is in the $\mathrm{N}+$ source, protected from the drain.

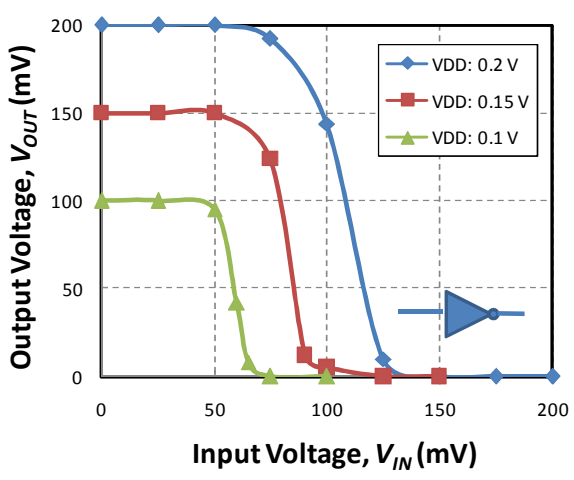

Fig. 18. $\mathrm{P} / \mathrm{N}$ type gFETs of Fig. 17 with $\mathrm{Eg}=0.36 \mathrm{eV}$ produce excellent simulated inverter transfer curves even at $0.1 \mathrm{~V}[1]$.

\begin{tabular}{|c|c|c|c|}
\hline & $\begin{array}{c}\text { Ref. } \\
{[10]}\end{array}$ & $\begin{array}{l}\text { Ref. } \\
{[11]}\end{array}$ & $\begin{array}{c}\text { Ref. } \\
{[12]}\end{array}$ \\
\hline$\Delta \mathbf{E}_{\mathrm{C}}$ & 0.55 & 0.57 & 0.58 \\
\hline$\Delta \mathbf{E}_{\mathbf{V}}$ & 0.31 & 0.25 & 0.21 \\
\hline $\mathbf{E}_{\mathrm{g}, \mathrm{s}-\mathrm{Si}}$ & 0.42 & 0.35 & 0.37 \\
\hline $\mathbf{E}_{\mathrm{g}, \text { eff }}$ & 0.19 & 0.17 & 0.16 \\
\hline
\end{tabular}

Fig. 21. Theoretical $\mathrm{E}_{\text {geff }}$ of a Ge-strained $\mathrm{Si}$ gFET is around $0.18 \mathrm{eV}$, good for $\mathrm{V}_{\mathrm{DD}}<0.1 \mathrm{~V}$ operation (see Fig. 17).

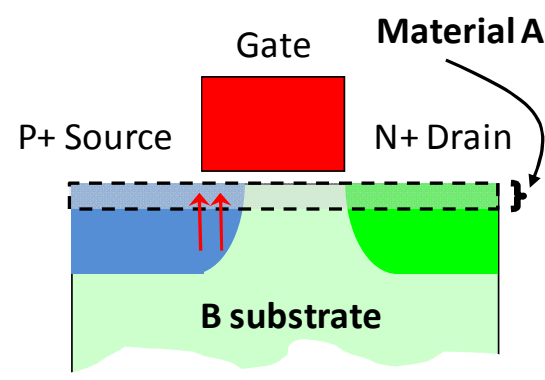

Fig. 19. A heterojunction gFET [9]. See Fig. 20 for explanation.

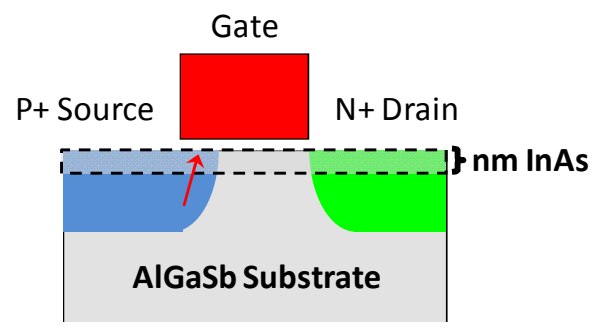

Fig. 22. gFET may employ heterojunction of compound semiconductor with tunable $\mathrm{E}_{\text {geff }}$. 